\title{
Prevalence and predictors of metabolic syndrome among women above 35 years of age: a cross sectional study from northern India
}

\author{
Era Claudius ${ }^{1}$, Kavita Mandrelle ${ }^{1}$, Mary John $^{2},{\text { Shavinder } \operatorname{Singh}^{3}}^{3}$
}

\author{
${ }^{1}$ Department of Obstetrics \& Gynaecology, Christian Medical College and Hospital, Ludhiana, Punjab \\ ${ }^{2}$ Department of Medicine, Christian Medical College and Hospital, Ludhiana, Punjab \\ ${ }^{3}$ Department of Social and Preventive Medicine, Christian Medical College and Hospital, Ludhiana, Punjab
}

Received: 14 February 2016

Revised: 14 March 2016

Accepted: 15 March 2016

\author{
*Correspondence: \\ Dr. Era Claudius, \\ E-mail: era.grace.4@gmail.com
}

Copyright: (C) the author(s), publisher and licensee Medip Academy. This is an open-access article distributed under the terms of the Creative Commons Attribution Non-Commercial License, which permits unrestricted non-commercial use, distribution, and reproduction in any medium, provided the original work is properly cited.

\begin{abstract}
Background: In India, as more and more people are adopting sedentary lifestyle the prevalence of metabolic syndrome is increasing. Metabolic syndrome (MS) is a cluster of risk factors for future development of type 2 diabetes mellitus and cardiovascular diseases. The objectives of the study was to determine prevalence of metabolic syndrome among women above age of 35 years in northern India attending a gynecological outpatient department of a tertiary hospital and to find out predictors of metabolic syndrome.

Methods: Premenopausal and postmenopausal women above 35 years of age attending gynecological outpatient department were screened for the presence of metabolic syndrome, according to the criteria of modified NCEP-ATP III (National Cholesterol Education Program). Data was collected and analyzed. A p-value <0.05 was considered statistically significant.

Results: The prevalence of metabolic syndrome was $49.3 \%$ among women above 35 years of age. In the logistic regression analysis it is found that body mass index and menopausal status were two variables which significantly affected occurrence of metabolic syndrome.

Conclusions: The present study shows a high prevalence of metabolic syndrome amongst women above 35 years of age. The prevalence was higher in postmenopausal women than in premenopausal women. In logistic regression analysis it was found that menopause and body mass index are independent predictors of metabolic syndrome.
\end{abstract}

Keywords: MS, Menopause, NCEP-ATP III

\section{INTRODUCTION}

The rapid rise of non-communicable diseases is presenting a formidable challenge in 20th century which is threatening economic and social development of the world as well as the lives and health of millions across the globe. ${ }^{1}$ Today, cardiovascular disease is one of the main causes of mortality of women in the world. ${ }^{2}$ Considering the metabolic changes that occur in women during menopause, there is an increase in risk factors of cardiovascular diseases and incidence of these diseases in post menopause. Some believe that the increased incidence occurs just by increased age but some studies demonstrated the fourfold increase in incidence of cardiovascular diseases in post-menopause. ${ }^{3}$

Metabolic syndrome is a cluster of components which make the individual susceptible to Cardio vascular diseases. These components are: increased lipid accumulation in central parts of the body (abdominal obesity), insulin resistance (IR), dyslipidaemia (elevated triglyceride and LDL and decreased HDL), and hypertension. According to modified NCEP-ATP III criteria (National Cholesterol Education Program- Adult Treatment Panel III), presence of at least three of these components is considered metabolic syndrome. ${ }^{4}$ 


\section{METHODS}

After clearance from ethics committee, women above 35 years of age attending gynaecology outpatient department were included. Women who received hormone replacement therapy, or oral contraceptive in last 3 months and who were pregnant were excluded. Metabolic syndrome was defined according to modified NCEP-ATP III criteria.

After an informed consent a standard questionnaire was used. Anthropometric measurements included a waist circumference in centimetres measured at the narrowest circumference, midway between the upper border of iliac crest and the lower rib margin, whereas the hip circumference was taken as the widest measurement at the level of the greater trochanters. Height was recorded in centimetres and weight in kilograms. Body mass index (BMI) was calculated as weight in kilograms divided by the square of height in meters $\left(\mathrm{kg} / \mathrm{m}^{2}\right)$. Overweight was defined as a BMI between 25.0 and 29.9 and obese as 30.0 or higher according to World Health Organization categories. Sitting blood pressure was measured after a 5min rest using a standard sphygmomanometer.

\section{Laboratory method}

Blood samples were collected by venepuncture after an overnight fast for 8-12hours. Venous blood was collected for measurement of serum lipids (triglycerides and HDLC) and fasting blood glucose, respectively. The analysis was carried on an automated clinical chemistry analyser.

\section{Data analysis and statistical methods}

Data was entered in Epidata entry version 3.1 and analysed using Epianalysis version 2.2.2 and Epi info 7. Proportions, Chi square and logistic regression were used to analyse the data.

\section{RESULTS}

The total number of women enrolled in the study were 300 , among which majority were in the age group of 35 44 years $(45.3 \%)$. The mean age of the women in study population was 47.3 years. According to menopausal status 188 women were postmenopausal and 112 women were premenopausal. The mean age of the menopause in the study population was 48.9 years.

Table 1: Components of metabolic syndrome in women (modified NCEP-ATP III).

\begin{tabular}{|c|c|c|}
\hline Component & Value & $\begin{array}{l}\text { Metabolic } \\
\text { Syndrome }\end{array}$ \\
\hline $\begin{array}{l}\text { Waist } \\
\text { circumference } \\
\text { (Central } \\
\text { obesity) }\end{array}$ & $\geq 80 \mathrm{~cm}$ & \multirow{5}{*}{$\begin{array}{l}\text { Any } 3 \text { criteria } \\
\text { should be } \\
\text { present }\end{array}$} \\
\hline Triglycerides & $\begin{array}{l}\geq 150 \mathrm{mg} / \mathrm{dl} \text { Or } \\
\text { on treatment for } \\
\text { Dyslipidaemia }\end{array}$ & \\
\hline HDL-C & $\begin{array}{l}<50 \mathrm{mg} / \mathrm{dl} \text { Or } \\
\text { under treatment for } \\
\text { Dyslipidaemia }\end{array}$ & \\
\hline $\begin{array}{l}\text { Blood } \\
\text { Pressure: } \\
\text { Systolic BP } \\
\text { diastolic BP }\end{array}$ & $\begin{array}{l}>130 \mathrm{~mm} \mathrm{Hg} \\
>85 \mathrm{~mm} \mathrm{Hg} \mathrm{Or} \\
\text { treatment of } \\
\text { previously } \\
\text { diagnosed } \\
\text { hypertension }\end{array}$ & \\
\hline $\begin{array}{l}\text { Fasting blood } \\
\text { glucose }\end{array}$ & $\begin{array}{l}\geq 100 \mathrm{mg} / \mathrm{dl} \mathrm{Or} \\
\text { previously } \\
\text { diagnosed } \\
\text { diabetic on } \\
\text { treatment }\end{array}$ & \\
\hline
\end{tabular}

Table 2: Predictors of metabolic syndrome.

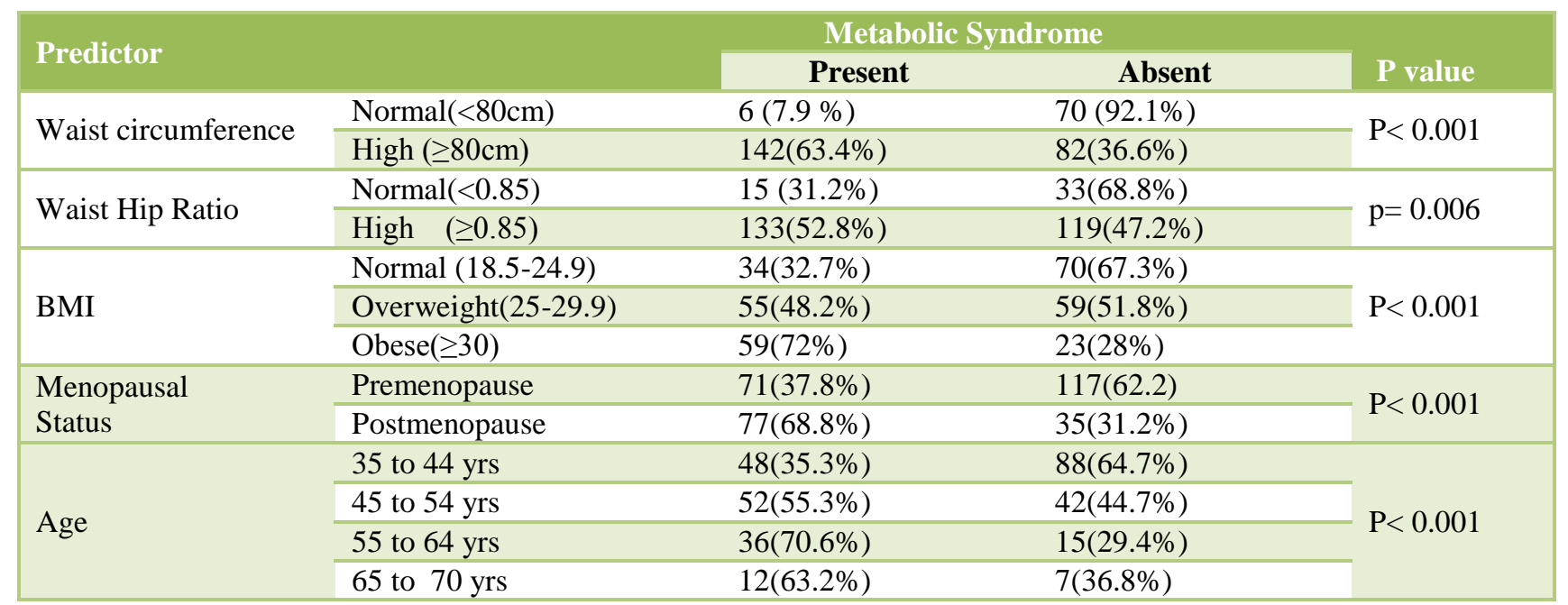


Table 3: Logistic regression analysis showing the predictive association of clinical variables and presence of metabolic syndrome.

\begin{tabular}{|llllllll|}
\hline Term & Odds Ratio & $95 \%$ & C.I. & Coefficient & S. E. & Z-Statistic & P-Value \\
\hline Age & 1.0203 & 0.9711 & 1.0720 & 0.0201 & 0.0252 & 0.7975 & 0.4252 \\
\hline Body mass index & 1.1622 & 1.0896 & 1.2397 & 0.1504 & 0.0329 & 4.5651 & 0.0000 \\
\hline Parity & 1.3848 & 0.9058 & 2.1173 & 0.3256 & 0.2166 & 1.5032 & 0.1328 \\
\hline Menopausal status & 2.7932 & 1.0693 & 7.2960 & 1.0272 & 0.4899 & 2.0968 & 0.0360 \\
\hline Waist Hip ratio & 31.9676 & 0.8096 & 1262.3097 & 3.4647 & 1.8755 & 1.8473 & 0.0647 \\
\hline Constant & $*$ & $*$ & $*$ & 0.6083 & 270.8683 & 0.0022 & 0.9982 \\
\hline
\end{tabular}

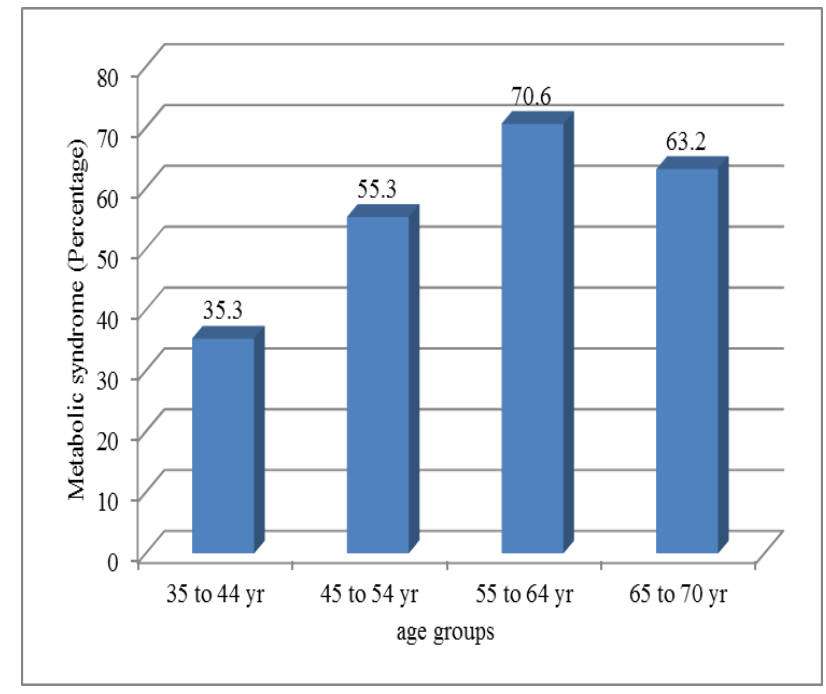

Figure 1: Distribution of study cases according to age and metabolic syndrome.

Overall prevalence of metabolic syndrome in our study was found to be $49.3 \%(n=148)$. In age group of $35-44$ years $35.3 \%$ of woman had metabolic syndrome, in age group of $45-54$ years $55.5 \%$, in the age group of 55-64 years $70.6 \%$ and in the age group of $>65$ years $63.2 \%$ had metabolic syndrome.

Metabolic syndrome was found to be present in $37.8 \%$ of premenopausal women and $68.8 \%$ of postmenopausal women and as the order of parity increases the prevalence of metabolic syndrome increases.

The prevalence of metabolic syndrome in women with normal body mass index was found to be $32.7 \%$. In overweight and obese women it was found to be $48.2 \%$ and $72 \%$ respectively.

Increase in prevalence of metabolic syndrome with increase in waist circumference was also observed among the study cases $(\mathrm{p}<0.05)$. In the current study metabolic syndrome was present in $63.4 \%$ of cases with increased waist circumference $(\geq 80 \mathrm{~cm})$ in comparison to $7.9 \%$ with normal waist circumference.
In all study cases it is seen that as waist hip ratio increases prevalence of metabolic syndrome also increases. Metabolic syndrome was present in $52.8 \%$ of study cases who had high waist to hip ratio $(\geq 0.85)$ in comparison to $31.3 \%$ in normal waist ratio.

In the logistic regression analysis it is found that body mass index and menopausal status were two variables which significantly affected occurrence of metabolic syndrome $(\mathrm{p}<0.05)$. Various other factors like age, parity and waist hip ratio which was statistically significant in single variant analysis lost its significance in the logistic regression analysis.

\section{DISCUSSION}

The prevalence of metabolic syndrome was $49.3 \%$ among women above 35 years of age attending gynaecology OPD. The prevalence was highest $(70.6 \%)$ among age group of 55-64 years. In the age group of 35-44 years prevalence was $35.3 \%$ followed by $55.5 \%$ in age group of 45-54 years which is similar to $34.5-73.7 \%$ reported in the literature. ${ }^{5}$ It was also seen that as age increased, prevalence of metabolic syndrome had also increased. ${ }^{6}$

Multiparity poses significant risk for development of metabolic syndrome. ${ }^{7}$ In present study also it was noticed that as parity increases the prevalence of metabolic syndrome has also increased. Various other studies also support this positive correlation. ${ }^{8,9}$

Menopause is an important predictor of metabolic syndrome. In present study it is found that postmenopausal women had significantly higher prevalence of metabolic syndrome in comparison to premenopausal women $(68.8 \%$ vs $37.8 \%)$ and on statistical correlation it was found to be statistically significant $(\mathrm{p}<0.05)$. Results of the present study are consistent with other studies in literature..$^{10-13}$

In present study it was seen that as body mass index increases prevalence of metabolic syndrome also increases significantly. Metabolic syndrome was present in $32.7 \%$ of women who had normal BMI, among overweight woman $48.2 \%$ but among obese $72 \%$ women had metabolic syndrome. When it was statistically 
correlated, this difference was statistically significant. $(\mathrm{P}<0.05)$ Results of the present study is consistent with the Canton Diabetes and Metabolic Disorders Study, a population based cross-sectional study in which Liang $\mathrm{H}$ found that higher body mass index (BMI) is positively associated with metabolic syndrome. ${ }^{14}$ Similarly Sakurai $\mathrm{M}$ et al also found positive correlation between body mass index (BMI) and metabolic syndrome in Asian women. $^{15}$

It was seen that among those who had high waist Circumference had higher prevalence of metabolic syndrome in comparison to those who had normal waist Circumference only (63.4\% vs $7.9 \%)$. This positive association is in concordant with a study by Bener A et al who also found that there is significant correlation between waist circumference and metabolic syndrome and it can also effectively predict the risk of metabolic syndrome. $^{16}$

Results of the present study is similar to a study by Bener A et al who found that waist hip ratio was significantly higher among the participants with metabolic syndrome as compared to those without metabolic syndrome $(52.8 \%$ vs $31.3 \%){ }^{16}$

In logistic regression analysis various factors like age, parity and waist hip ratio which was statistically significant in single variant analysis lost its significance. It is found that BMI and menopausal status are two factors which significantly affect occurrence of metabolic syndrome. Logistic regression analysis revealed that prevalence of metabolic syndrome was 1.78 times higher in post-menopausal women than pre-menopausal women and menopause was an important predictor of metabolic syndrome. ${ }^{10,12,13}$

\section{CONCLUSION}

The present study shows a high prevalence of metabolic syndrome amongst women above 35 years of age. The prevalence was higher in postmenopausal women than in premenopausal women. In logistic regression analysis it was found that menopause and body mass index are independent predictors of metabolic syndrome.

\section{Funding: Not required}

Conflict of interest: None declared

Ethical approval: The study was approved by the Institutional Ethics Committee

\section{REFERENCES}

1. Upadhyay RP. An overview of the burden of noncommunicable diseases in India. Iranian journal of public health. 2012;41(3):1-8.

2. Lloyd-Jones D, Adams R, Carnethon M, De Simone G, Ferguson TB, Flegal K, et al. Heart disease and stroke statistics--2009 update: a report from the
American Heart Association Statistics Committee and Stroke Statistics Subcommittee. Circulation. 2009;119(3):480-6.

3. Carr MC. The emergence of the metabolic syndrome with menopause. The Journal of clinical endocrinology and metabolism. 2003;88(6):2404-11.

4. Executive Summary of the Third Report of the National Cholesterol Education Program (NCEP) Expert Panel on Detection, Evaluation, and Treatment of High Blood Cholesterol In Adults (Adult Treatment Panel III). JAMA: the journal of the American Medical Association. 2001;285(19):2486-97.

5. Prasad DS, Kabir Z, Dash AK, Das BC. Prevalence and risk factors for metabolic syndrome in Asian Indians: A community study from urban Eastern India. Journal of cardiovascular disease research. 2012;3(3):204-11.

6. Pandey S, Srinivas M, Agashe S, Joshi J, Galvankar $\mathrm{P}$, Prakasam CP, et al. Menopause and metabolic syndrome: A study of 498 urban women from western India. Journal of mid-life health. 2010;1(2):63-9.

7. Gude D. Multiparity: A double-edged blessing of metabolic syndrome along with children. Indian journal of endocrinology and metabolism. 2012;16(1):144-5.

8. Mousavi E, Gharipour M, Tavassoli A, Sadri GH, Sarrafzadegan N. Multiparity and risk of metabolic syndrome: Isfahan Healthy Heart Program. Metab Syndr Relat Disord. 2009;7(6):519-24.

9. Akter S, Jesmin S, Rahman MM, Islam MM, Khatun MT, Yamaguchi N, et al. Higher Gravidity and Parity Are Associated with Increased Prevalence of Metabolic Syndrome among Rural Bangladeshi Women. PLoS ONE. 2013;8(8):e68319.

10. Jesmin S, Islam AM, Akter S, Islam MM, Sultana SN, Yamaguchi N, et al. Metabolic syndrome among pre- and post-menopausal rural women in Bangladesh: result from a population-based study. BMC Res Notes. 2013;6:157.

11. Janssen I, Powell LH, Crawford S, Lasley B, SuttonTyrrell K. Menopause and the metabolic syndrome: the Study of Women's Health Across the Nation. Arch Intern Med. 2008;168(14):1568-75.

12. Ben Ali S, Belfki-Benali H, Aounallah-Skhiri H, Traissac P, Maire B, Delpeuch F, et al. Menopause and Metabolic Syndrome in Tunisian Women. BioMed Research International. 2014;2014:7.

13. Eshtiaghi R, Esteghamati A, Nakhjavani $M$. Menopause is an independent predictor of metabolic syndrome in Iranian women. Maturitas. 2010;65(3):262-6.

14. Liang H, Chen X, Chen Q, Wang Y, Wu X, Li Y, et al. The metabolic syndrome among postmenopausal women in rural Canton: prevalence, associated factors, and the optimal obesity and atherogenic indices. PLoS One. 2013;8(9):e74121.

15. Sakurai M, Takamura T, Miura K, Kaneko S, Nakagawa H. BMI may be better than waist 
circumference for defining metabolic syndrome in Japanese women. Diabetes care. 2008;31(3):e12.

16. Bener A, Yousafzai MT, Darwish S, Al-Hamaq AO, Nasralla EA, Abdul-Ghani M. Obesity index that better predict metabolic syndrome: body mass index, waist circumference, waist hip ratio, or waist height ratio. J Obes. 2013;2013:269038.
Cite this article as: Claudius E, Mandrelle K, John M, Singh S. Prevalence and predictors of metabolic syndrome among women above 35 years of age: a cross sectional study from northern India. Int $\mathbf{J}$ Reprod Contracept Obstet Gynecol 2016;5:1047-51. 